\title{
A cross sectional study on prevalence of depression and its socio-demographic correlates among elderly in rural India
}

\author{
Ramesh D. Pawar, ${ }^{1, *}$ Kalpana M. Kale ${ }^{2}$, Nandkeshav R Aswar ${ }^{3}$, Shital Solanke ${ }^{4}$ \\ ${ }^{1}$ Assistant Professor, ${ }^{\mathbf{2}, 3}$ Associate Professor and HOD, ${ }^{\mathbf{B}}$ Blood Transfusion Officer, ${ }^{\mathbf{1}-3}$ Dept. of Community Medicine, ${ }^{\mathbf{4}}$ Dept. of Blood Bank, \\ ${ }^{1-3}$ Government Medical College, Akola, Maharashtra, District General Hospital, Buldana, Maharashtra, India
}

*Corresponding Author: Ramesh D. Pawar

Email: ramm.pawar@gmail.com

\begin{abstract}
Introduction: India is presently undergoing demographic transition leading significant increase in elderly population. The advent of better health services and preventive care has raised life expectancy. Presently the population of elderly in India is $9.4 \%$ in 2017 which will rise to $19.1 \%$ in 2050 . Elderly form a vulnerable group as they suffer from physical, psychological, economic, social and nutritional problems. These problems there by con-tribute to various disabilities. Prevalence of depression among elderly ranges from as low as $12.7 \%$ to as high as $60.0 \%$ from literature. The depression among the elderly often goes undetected and thus untreated which results in loneliness, social isolation, cognitive impairment, and decline in their ability to carry out the functional activities and thus compromises their quality of life. Determining the burden of depression among the elderly and to study various sociodemographic factors will facilitate formulating policies to plan better health care delivery services for them. Hence present study was planned with the objective to study the magnitude of depression and its socio demographic correlates among the elderly.

Material and Methods: Present study was a cross sectional study conducted in elderly ( $\geq 60$ Years) residing in the field practice area of Rural Health Training Centre of one of the Government Medical College. Sample size calculated for the study was 290 and simple random sampling method was used for the data collection. Measurement was done using WHO Geriatric Depression Scale (GDS) long form of 30 questions. Ethical approval was obtained from institutional ethical committee and consent was taken from participants. Data entry and analysis was done by using software Epi Info version 7.2

Results: The Magnitude of Depression among elderly was found to be 57.66\% (Mild Depression 23.91\%, Moderate Depression $19.06 \%$ and Severe Depression 14.69\%). The various factors associated with depression were, female sex, low Socio-economic status, and single/widowed/divorced, less physical activity, inadequate sleep and living alone.

Conclusions: The high prevalence of depression observed among the elderly population suggests there is need for improvement in policies and guidelines for early screening, treatment and counselling of elderly for timely detection and treatment of depression at community level. Formation of social groups at community level and more emphasis on improvement of quality of life of the elderly.
\end{abstract}

Keywords: Depression, Elderly, Factors affecting depression, Geriatric depression scale -30 .

\section{Introduction}

Because of undergoing demographic transition in India it leads to significant increase in elderly population. ${ }^{1}$ The improvement and provision of good health services and preventive care has further raised the life expectancy. In 1980 worldwide population of elderly 60 years or above was 382 million which became more than double and presently in 2017 global population of 60 years or above is 962 millions and the number of older persons is expected to get double again and is projected to reach nearly 2.1 billion by $2050 .^{2}$ The older population of the developing regions is growing much faster than in the developed regions and projections 79 per cent of the world's population aged 60 or over will be living in the developing regions by $2015 .^{2}$ In India the population of elderly is $9.4 \%$ and it is expected to rise to $19.1 \%$ till $2015 .^{2}$ Elderly faces many problems which include physical problems, psychological problems, Nutritional Problems like Anaemia and malnutrition, Socioeconomic problems. ${ }^{3,4}$ These health problems lead to various disabilities and limitations in the future. ${ }^{5}$ Studies found that about one third of elderly are suffering from psychiatric illnesses and depression alone account for more than $50 \%$ them. ${ }^{6}$ From the previous literature the prevalence of depression among elderly ranges between $12 \%$ to $60 \%$ and it varies in rural and urban areas. ${ }^{7-11}$ Most of the time depression among elderly remains undetected and untreated leading to loneliness and social isolatation which ultimately results in poor quality of life. ${ }^{12,13}$ Determining the burden of depression among the elderly and to study various socio- demographic factors will facilitate formulating policies to plan better health care delivery services for them. Hence present study was planned to study the prevalence of depression among elderly and its socio-demographic correlates in rural Indian Population.

\section{Objective}

1. To study the prevalence of depression among elderly in rural areas

2. To study the correlates of Depression among elderly in rural areas

\section{Material and Methods}

Study settings: present study was a cross sectional study conducted under Department of Community Medicine of Government Medical College, Akola in rural filed practice area or Rural Health Training Centre, Barshi Takali between July to October 2018. Total population covered by Centre is of 10,750 .

Study Population: Elderly $\geq 60$ years (Both Males and Females) residing in the field practice area were included in the study.

Sample Size and Sampling Method: From pervious literature (a Study by Abhishek B et $\mathrm{al}^{10}$ ), by considering prevalence of depression as $25 \%$ among elderly population, 95\% CI and absolute precision of 5, sample size for the study was calculated by using formula $4 \mathrm{pq} / \mathrm{l}^{2}$ and it came out to be 287 hence we have included 290 participants in our study. RHTC (Rural Health Training Centre) has list of 
all the geriatric population residing in the field practice area. We use simple random sampling method for the selection of geriatric people. Out of the total 780 geriatric people residing in filed practice area, 300 were randomly selected for the study purpose using random number table. Informed consent was taken from the participants. 10 participants did not volunteer for participation in the study, so finally in analysis 290 participants were included.

Measurements: WHO's long form of 30 questions of Geriatric Depression Scale (GDS) was used for screening depression among elderly population. It has three grades Normal- (0-9 Score), Mild Depression (10-19 Score) Severe Depression (20-30 Score).

Data Collection Tool: Data collection tool was a predesign and semi structured Questionnaire which was prepared by using, Elderly's Status among different states In India which was published in 2011. To achieve the objectives slight modifications in the questionnaire were done.

Data Collection: List of elderly ( $\geq 60$ years of age) residing in the field practice area was obtained from RHTC. We use simple random sampling method for selection of participants. Random numbers were generated by using random number table and participants were interviewed by using study tool after obtaining informed consent.

Ethical Approval was taken from the institutional ethical committee and confidentiality was maintained thought the process. Patients detected for mild depression were counseled and that of severe depression were referred to psychiatrist for further treatment.

\section{Analysis}

Data Entry and analysis was done using statistical software Epi Info 7 and appropriate statistical test was applied to study the association between and dependent and independent variables.

\section{Results}

As shown in Table 1, Out of the 290 participants (144 Males and 146 Females) $68.27 \%$ were between the age group of $60-69$ years. $61.38 \%$ of the elderly were married and $38.62 \%$ were Widowed/separated/Divorced or Living Single. We found that $66.21 \%$ of the elderly were illiterate and only $31.03 \%$ were working. Majority of the elderly were belonging to Hindu religion (64.48\%) followed by Muslim Religion (32.76\%). We used modified BG Prasad classification to assess the socio-economic status. Majority $(46.55 \%)$ of the geriatric participants were falling in Class $\mathrm{V}$. In present study prevalence of depression among elderly was found to be $57.66 \%$. Mild Depression was found in $23.91 \%$ participants, moderate depression in $19.06 \%$ severe depression was found in $14.69 \%$ participants as depicted in (Table 2). In present study we found that depression was more common in 60 to 69 yrs of age group and there was statistically significant difference between depression and age groups. Females $(63.69 \%)$ significantly more depressed compared with males $(36.31 \%)$ as $\mathrm{p}$ value was $<0.05$ (Table $3)$. Depression was more among elderly who were either widowed or separated or living single $(54.17 \%)$ than elderly who were married $(45.83 \%)$ and living with their spouses and it was statistically significant $(\mathrm{p}<0.05)$. Although depression was more among illiterate $(>60.0 \%)$ but there was no statistically significant difference between education and depression. Depression was significantly lower among the elderly who were doing regular exercises $(41.07 \%)$ as shown in (Table 4). Considering the living conditions, Depression was more among elderly who were either alone $(82.00 \%)$ or staying with relatives $(81.82 \%)$ as compared with elderly who were staying with spouse $(46.15 \%)$ or children $(63.24 \%)$ as Shown in (Table 5).

Table1: Distribution of participants according to basic demographic factors

\begin{tabular}{|l|c|c|c|}
\hline Socio Demographic Factors & $\begin{array}{c}\text { Males } \\
(\mathbf{n = 1 4 4})\end{array}$ & $\begin{array}{c}\text { Females } \\
(\mathbf{n = 1 4 6})\end{array}$ & $\begin{array}{c}\text { Total } \\
(\mathbf{N}=\mathbf{2 9 0})\end{array}$ \\
\hline Age Group & $94(65.28)$ & $104(71.23)$ & $198(68.27)$ \\
\hline $60-69$ & $41(28.47)$ & $31(21.23)$ & $72(24.83)$ \\
\hline $70-79$ & $9(6.25)$ & $11(7.54)$ & $20(6.90)$ \\
\hline$\geq 80$ & $144(49.66)$ & $146(50.34)$ & $290(100.00)$ \\
\hline Total & & & \\
\hline Marital Status & & & $7(2.41)$ \\
\hline Single & $5(3.47)$ & $2(1.37)$ & $178(61.38)$ \\
\hline Married & $108(75.00)$ & $70(47.94)$ & $102(35.18)$ \\
\hline Widowed & $29(20.13)$ & $73(50.00)$ & $3(1.03)$ \\
\hline Separated & $2(1.39)$ & $1(0.67)$ & $290(100.00)$ \\
\hline Total & $144(49.66)$ & $146(50.34)$ & \\
\hline & & & $187(64.48)$ \\
\hline Religion & & & $95(32.76)$ \\
\hline Hindu & $96(66.67)$ & $91(62.33)$ & $8(2.76)$ \\
\hline Muslim & $44(30.55)$ & $51(34.93)$ & $290(100.00)$ \\
\hline Christians & $4(2.78)$ & $4(2.74)$ & \\
\hline Total & $144(49.66)$ & $146(50.34)$ & \\
\hline
\end{tabular}




\begin{tabular}{|l|c|c|c|}
\hline & & & \\
\hline Educational Qualification & & & \\
\hline Illiterate & $80(55.56)$ & $112(76.71)$ & $192(66.21)$ \\
\hline Literate & $64(44.44)$ & $34(23.29)$ & $98(33.79)$ \\
\hline Total & & & \\
\hline & $144(49.66)$ & $146(50.34)$ & $290(100.00)$ \\
\hline Current occupational status & & & \\
\hline Working & $46(31.94)$ & $44(30.14)$ & $90(31.03)$ \\
\hline Not working & $98(68.06)$ & $102(69.86)$ & $200(68.97)$ \\
\hline Total & $144(49.66)$ & $146(50.34)$ & $290(100.00)$ \\
\hline
\end{tabular}

Table 2: Grading of depression in elderly according to geriatric depression scale (GSD-15)

\begin{tabular}{|l|c|}
\hline Grading of Depression & Frequency \\
\hline Absent & $271(42.34)$ \\
\hline Mild & $153(23.91)$ \\
\hline Moderate & $122(19.06)$ \\
\hline Severe & $94(14.69)$ \\
\hline Total & $640(100)$ \\
\hline
\end{tabular}

Table 3: Grading of Depression and Demographic factors

\begin{tabular}{|c|c|c|c|c|c|c|}
\hline Demographic & \multicolumn{4}{|c|}{ Grades of Depression } & \multirow[t]{2}{*}{ Total } & \multirow[t]{2}{*}{ P Value } \\
\hline Age (In Years ) & Absent & Mild & Moderate & Severe & & \\
\hline $60-69$ & $94(77.05)$ & $54(77.14)$ & $31(55.36)$ & $19(45.24)$ & $198(68.27)$ & \multirow{4}{*}{$\begin{array}{c}\mathrm{X} 2=14.27, \\
\mathrm{df}=2, \\
\mathrm{P}<0.05\end{array}$} \\
\hline $70-79$ & $27(22.13)$ & $11(15.72)$ & $17(30.36)$ & $16(38.09)$ & $72(24.83)$ & \\
\hline$\geq 80-89$ & $1(0.82)$ & $5(7.14)$ & $8(14.28)$ & $7(16.67)$ & $20(6.90)$ & \\
\hline Total & $122(42.07)$ & $70(24.14)$ & $56(19.31)$ & $42(14.48)$ & $290(100.00)$ & \\
\hline \multicolumn{7}{|l|}{$\begin{array}{l}\text { Depression and } \\
\text { Gender }\end{array}$} \\
\hline Males & $83(68.03)$ & $25(35.71)$ & $24(42.86)$ & $12(28.57)$ & $144(49.66)$ & \multirow{2}{*}{$\begin{array}{c}\mathrm{X} 2=28.45 \\
\mathrm{Df}=1 \\
\mathrm{P}<0.05\end{array}$} \\
\hline Females & $39(31.97)$ & $45(64.29)$ & $32(57.14)$ & $30(71.43)$ & $146(50.34)$ & \\
\hline Total & $122(42.07)$ & $70(24.14)$ & $56(19.31)$ & $42(14.48)$ & $290(100.00)$ & \\
\hline \multicolumn{7}{|l|}{$\begin{array}{l}\text { Depression and } \\
\text { Marital Status }\end{array}$} \\
\hline Married & $101(82.79)$ & $45(64.28)$ & $16(28.57)$ & $16(38.09)$ & $178(61.38)$ & \multirow{2}{*}{$\begin{array}{c}\mathrm{X} 2=40.71, \\
\mathrm{df}=1, \mathrm{P}<0.05\end{array}$} \\
\hline $\begin{array}{l}\text { Widowed/Separat } \\
\text { ed /single }\end{array}$ & 21(17.21) & $25(35.72)$ & $40(71.43)$ & $26(61.91)$ & $112(38.62)$ & \\
\hline Total & $122(42.07)$ & $70(24.14)$ & $56(19.31)$ & $42(14.48)$ & $290(100.00)$ & \\
\hline \multicolumn{7}{|l|}{$\begin{array}{l}\text { Depression and } \\
\text { Educational } \\
\text { Qualification }\end{array}$} \\
\hline Illiterate & $74(60.66)$ & $48(68.57)$ & $40(71.43)$ & $30(71.43)$ & $192(66.21)$ & \multirow{3}{*}{$\begin{array}{c}\mathrm{X} 2=2.9006 \\
\mathrm{Df}=1 \\
\mathrm{P}>0.05\end{array}$} \\
\hline Literate & $48(39.34)$ & $22(31.43)$ & $16(28.57)$ & $12(28.57)$ & $98(33.79)$ & \\
\hline Total & $122(42.07)$ & $70(24.14)$ & $56(19.31)$ & $42(14.48)$ & $290(100.00)$ & \\
\hline
\end{tabular}

Table 4: Grading of depression, physical activity and adequacy of sleep

\begin{tabular}{|c|c|c|c|c|c|c|}
\hline Depression and & \multicolumn{4}{|c|}{ Grades of Depression } & & \\
\hline & Absent & Mild & Moderate & Severe & Total & \\
\hline Yes & $91(74.59)$ & $46(65.71)$ & $27(48.21)$ & $26(61.90)$ & $190(65.52)$ & $\mathrm{X} 2=7.6734$ \\
\hline No & $31(25.41)$ & $24(34.29)$ & $29(51.79)$ & $16(38.10)$ & $100(34.48)$ & $\begin{array}{l}\mathrm{Df}=1 \\
\mathrm{P}<0.05\end{array}$ \\
\hline Total & $122(42.07)$ & $70(24.14)$ & $56(19.31)$ & $42(14.48)$ & $290(100.00)$ & \\
\hline
\end{tabular}




\begin{tabular}{|c|c|c|c|c|c|c|}
\hline $\begin{array}{l}\text { Depression and } \\
\text { adequacy of sleep }\end{array}$ & & & & & & \\
\hline Adequate & $90(73.77)$ & $39(55.71)$ & $10(17.86)$ & $12(28.57)$ & 151 (50.07) & \multirow{2}{*}{$\begin{array}{c}\mathrm{X} 2=39.7405 \\
\mathrm{Df}=1 \\
\mathrm{P}<0.05\end{array}$} \\
\hline Inadequate & $32(26.2)$ & $31(44.29)$ & $46(82.14)$ & $30(71.43)$ & $139(47.93)$ & \\
\hline Total & $122(42.07)$ & $70(24.14)$ & $56(19.31)$ & $42(14.48)$ & $290(100.00)$ & \\
\hline
\end{tabular}

Table 5: Distribution of participants according to Grades of Depression and living conditions

\begin{tabular}{|c|c|c|c|c|c|c|}
\hline Living Conditions & \multicolumn{4}{|c|}{ Grades of Depression } & & \\
\hline & Absent & Mild & Moderate & Severe & Total & \multirow{6}{*}{$\begin{array}{c}\mathrm{X} 2=23.7601 \\
\mathrm{D}=4 \\
\mathrm{P}<0.05\end{array}$} \\
\hline Alone & $9(7.38)$ & $10(14.29)$ & $13(23.21)$ & $18(42.86)$ & $50(17.24)$ & \\
\hline Spouse & $35(28.69)$ & $12(17.14)$ & $8(14.29)$ & $10(23.81)$ & $65(22.41)$ & \\
\hline Children & $25(20.49)$ & $20(28.57)$ & $17(30.36)$ & $6(14.29)$ & $68(23.44)$ & \\
\hline Spouse and Children & $51(41.80)$ & $25(35.71)$ & $14(25.00)$ & $6(14.29)$ & $96(33.10)$ & \\
\hline Relatives & $2(1.64)$ & $3(4.29)$ & $4(7.14)$ & $2(4.75)$ & $11(3.79)$ & \\
\hline Total & $122(42.07)$ & $70(24.14)$ & $56(19.31)$ & $42(14.48)$ & $290(100.00)$ & \\
\hline
\end{tabular}

\section{Discussion}

The Prevalence of depression among elderly was (57.66\%) among of which $23.91 \%$ were suffering from mild depression, $19.06 \%$ from moderate depression and $14.69 \%$ were suffering from severe depression. Similar finding were reported by Nirgude et $\mathrm{al}^{14}(59.6 \%)$, Maulik $\mathrm{S}$ et $\mathrm{al}^{15}$ $(53.0 \%)$, Naik P et al ${ }^{13}(59.6 \%)$, Res. Bras et ${ }^{16}(40.0 \%)$. In Present study depression was more among 60- 69 age group $(83.5 \%)$ similar findings was reported in study by Barua A $\mathrm{et}^{17}$ al and Cole $\mathrm{MG}^{18}$ et al in which they reported the depression was more common in 60-70 years of age group. In present study Depression was more common in females compared with males and the difference was statistically significant $(\mathrm{p}<0.05)$ Similar findings were reported by Barua $\mathrm{A}$ et $\mathrm{al}^{17}$ (Depression: Males $35.20 \%$ and Females $64.80 \%$ ) and Radhakrishnan $\mathrm{S}$ et $\mathrm{al}^{19}$ (Depression: Males $42.00 \%$ and females $58.00 \%$ ). Majority $(46.55 \%)$ of the elderly who had depression were belonging to Class-V Socio-economic status according to Modified BG Prasad Classification; Similar findings were observed in study by Maulik et al. ${ }^{15}$ Studies have found that education was one of the factor associated with depression. ${ }^{17}$ In a systematic review authors found the differences between association of depression and education. ${ }^{18,20-23}$ In our study although depression was more among illiterate $(>60.0 \%)$ but it was not significantly associated ( $>0.05)$ as shown in (Table 3) the difference in study could be due differences in study settings and socio cultural factors which differ in different settings. In Present study depression was found to be more among elderly who were sinlges/ widowed/ divorced $(54.17 \%)$ compared with elderly who were married $(45.83 \%)$ and it was statistically significant $(\mathrm{P}=<0.05)$. Similar findings were observed in other studies..$^{15,19,20,24-28}$ In our study we found elderly involved in physical activity were less depressed $(52.11 \%)$ compared with elderly not doing regular physical activity $(69.00 \%)$ and the difference was found to be statistically significant. Similar results were observed in study by Goswami et $\mathrm{al}^{29}$ and Sharma $\mathrm{R}$ et al. ${ }^{11}$ Inadequacy of sleep also contributes to depression; in our study we found that elderly having history of inadequate sleep were found to be significantly $\mathrm{p}(<0.05)$ more depressed (61.69\%) compared with elderly who had history of adequate sleep (38.31\%). our findings were consistent with the study by Kanimozhi $\mathrm{S}$ et al. ${ }^{30}$ In present study Depression was found to be more among elderly who were living alone $(82.00 \%)$ or with relatives $(81.82 \%)$ compared with the elderly who were living with spouse or children (below 47\%) as shown in (Table 6) and it was statistically significant $(\mathrm{p}<0.05)$. similar result were observed in study by Kanimozhi $\mathrm{S}$ et al. ${ }^{30}$

\section{Conclusions}

Prevalence of Depression among elderly was found to be $(57.66 \%)$ in rural area. The higher prevalence of depression observed among the elderly population is a serious concern. Screening of the elderly on mass scale is definitely going to help to detect the cases at earlier stages so that effective interventions can be planned to limit further disability and limitations. Presently no clear guidelines are available for screening hence many patients remains undetected and untreated. There is need for improvement in policies and guidelines for screening, treatment and counselling for timely detection and treatment of depression at community level. The various factors associated with depression in our study were aged, female sex, low Socioeconomic status, single/widowed/divorced, less physical activity, inadequate sleep, living alone or with relatives. Depression among elderly who are either singles or Widowed or divorced as well as inadequate physical activity and inadequate sleep suggest that there is need of formation of more and more social groups at community level to improve the quality of life through meditation-relaxation techniques, more interaction, exchange of thought and problem solving among the peer groups. Various government schemes are available but because of illiteracy and strict norms; many of the elderly did not get the benefits of the schemes. Social security Schemes has to be revised and initiatives have to be taken for community participation. The NGOs and other voluntary workers have the role for facilitation in the process. High prevalence among the 
elderly who are alone suggests the need of family support. The health care providers and patient's family members need to be trained and educated regarding elderly depression. More emphasis should be given on improvement of quality of life of the elderly through holistic approach in which efforts are to be put not only by elderly but also their families, health related sectors and the government.

\section{References}

1. Seby K, Chaudhury S, Chakraborty R; Prevalence of psychiatric and physical morbidity in an urban geriatric population. Indian J Psychiatry. 2011;53(2):121.

2. United Nations, Department of Economic and Social Affairs, Population Division (2017). World Population Ageing 2017 Highlights (ST/ESA/SER.A/397)

3. Prakash R, Choudhary S K, Singh U S. A Study of Mor-bidity Pattern among Geriatric Population in an Urban Area of Udaipur Rajasthan. IJCM. 2004;29(1):35-40.

4. Kishore S, Garg B S. Socio Medical Problems of Aged Population in a Rural Area of Wardha District. Indian J Public Health. 1997;41(1):43.

5. Joshi K, Kumar R, Avasthi A. Morbidity profile and its relationship with disability and psychological distress among elderly people in Northern India. Int J Epidemiol. 2003;32:978-987.

6. Dey A B, Soneja S, Nagarkar K M, Jhingan HP. Evaluation of the health and functional status of older Indians as a prelude to the development of a health programme. Natl Med J India. 2001;14:135-38.

7. Sherina MS, Rampal L, Mustaqim A. The prevalence of depression among the elderly in Sepang, Selangor. Med $J$ Malaysia. 2004;59:45-49

8. Rajkumar AP, Thangadurai P, Senthilkumar P, Gayathri K, Prince M, Jacob KS, et al. Nature, prevalence and factors associated with depression among the elderly in a rural south Indian community. Int Psychogeriatr. 2009;21:372-378.

9. MaulikS, Dasgupta A. Depression and its determinants in the rural elderly of West Bengal: A cross sectional study. Int J Biol Med Res. 2012;3:1299-302.

10. Naik Poonam, Nirgude Abhay. Depression among elderly: A Cross Sectional Study in a rural Community of South India. Natl J Community Med. 2015;6(2):394-397.

11. Sharma R, Sharma R. Depression Among the Elderly Population in a Rural Community: A Study of its Prevalence and Correlates. Indian Med Gazette. 2012;467-472.

12. Jariwala V, Bansal Rk, Patel S, Tamakuwala Bimal. A Study of Depression Among Aged In Surat City. Natl J Community Med. 2010;1(1):47-49.

13. Naik PR, Nirgude AS. Depression among the Elderly: A Cross Sec-tional Study In A Rural Community of South India. Natl J of Community Med. 2015;6(3):394-397.

14. Nirgude A, Naik P. Depression among the Elderly: A Cross Sectional Study In A Rural Community Of South India. Natl J Community Med. 2015;6(2);2015.

15. Maulik S, Dasgupta A. Depression and its determinants in the rural elderly of West Bengal -a cross sectional study. Int J Biol Med Res. 2012; 3(1):1299-1302.

16. Rev. Bras. Depressive disorders and comorbidities among the elderly: a population-based study. Geriatr Gerontol Rio de Janeiro. 2016;19(1):95-103.
17. Barua A, Ghosh MK, Kar N, Basilio MA. Sociodemographic factors of geriatric depression. Indian J Psychol Med 2010;32(2):87-92.

18. Cole MG, Dendukuri N. Risk Factors for depression among elderly community subjects: a systematic review and metaanalysis. Am J Psychiatr. 2003;160(6):1147-1156.

19. Radhakrishnan S, Nayeem A. Prevalence of depression among geriatric population in a rural area in Tamilnadu. Int $J$ Nutr Pharmacol Neurol Dis. 2013;3:309-12.

20. Imran A, Azidah AK, Asrenee AR, Rosediani M (2009) Prevalence of Depression and its Associated Factors among Elderly Patients in Outpatient Clinic of Universiti Sains Malaysia Hospital. Med J Malaysia. 164:134-139.

21. Chui PY, Chan MH. Prevalence of depressive symptoms and associated factors in patients attending geriatric hospital. Asian J Gerontol Geriatr. 2006;1:73-77.

22. Al-Shammari SA, Al-Subaie A (1999) Prevalence and correlates of depression among Saudi elderly. Int J Geriatr Psychiatry 14: 739-747.

23. Girma M, Hailu M, Wakwoya A, Yohannis Z, Ebrahim J (2016) Geriatric Depression in Ethiopia: Prevalence and Associated Factors. J Psychiatry. 20: 400. doi: 10.4172/23785756.1000400 .

24. World Health Organization and Calouste Gulbenkian Foundation. Social determinants of mental health. Geneva, World Health Organization, 2014.

25. Malhotra R, Chan A, Ostbye T (2010) Prevalence and correlates of clinically significant depressive symptoms among elderly people in Sri Lanka. Int Psychogeriatr. 2010;22:227236.

26. Girma M, Hailu M, Wakwoya A, Yohannis Z, Ebrahim J (2016) Geriatric Depression in Ethiopia: Prevalence and Associated Factors. J Psychiatry. 20:400. doi: 10.4172/23785756.1000400.

27. Itrat A, Taqui AM, Qazi F, Qidwai W (2007) Family systems: perceptions of elderly patients and their attendents presenting at a university hospital in Karachi Pakistan. J Pak Med Assoc. 2007;57:106-110

28. Al-Shammari SA, Al-Subaie A (1999) Prevalence and correlates of depression among Saudi elderly. Int J Geriatr Psychiatry. 1999;14:739-747.

29. Goswami S, Deshmukh PR, Pawar R, Raut AV, Bhagat M, Mehendale AM. Magnitude of depression and its correlates among elderly population in a rural area of Maharashtra: A cross-sectional study. J Family Med Prim Care. 2017;6:803812.

30. Kanimozhi S, Darbastwar MA. Prevalence of depression in the elderly population of rural Puducherry: a community based cross sectional study. Int J Community Med Public Health. 2017:4:4315-4320.

How to cite this article: Pawar R. D, Kale K. M, Aswar N. R, Solanke S. A cross sectional study on prevalence of depression and its socio-demographic correlates among elderly in rural India. Indian $\mathbf{J}$ Forensic Community Med. 2018;5(4):210-214. 